\title{
Condições de vida de mulheres quilombolas e o alcance da autonomia reprodutiva
}

\author{
Living conditions of quilombo women and the achievement of reproductive autonomy \\ Condiciones de vida de mujeres de palenques y el alcance de la autonomía reproductiva
}

Elionara Teixeira Boa Sorte Fernandes ${ }^{1}$ (C) Sílvia Lúcia Ferreira² (1) Cláudia Suely Barreto Ferreira ${ }^{3}$ (C) Verônica Barreto Cardoso ${ }^{4}$ (b)

1. Universidade do Estado da Bahia, Departamento de Educação. Guanambi, BA. Brasil.

2. Universidade Federal da Bahia, Escola de Enfermagem. Salvador, BA. Brasil.

3. Universidade do Estado da Bahia, Departamento de Educação. Senhor do Bonfim, BA. Brasil.

4. Maternidade Climério de Oliveira. Salvador, BA, Brasil.
Autor correspondente:

Elionara Teixeira Boa Sorte Fernandes

E-mail: naratbsorte@gmail.com

Recebido em 14/05/2020.

Aprovado em 21/09/2020.

DOI:https://doi.org/10.1590/2177-9465-EAN-2020-0147

\section{Resumo}

Objetivo: explicar a interferência das condições de vida de mulheres quilombolas na autonomia reprodutiva. Método: trata-se de um estudo qualitativo com 10 mulheres quilombolas com idade entre 23 e 49 anos, residentes em comunidades rurais do Território de Identidade da Bahia Sertão Produtivo. Estas compareceram aos encontros e assinaram o Termo de Consentimento Livre e Esclarecido. Os dados foram coletados através de grupos focais e analisados pela análise temática de Bardin. O software NVivo foi utilizado para organização dos dados. Procedeu-se à coleta de dados após a aprovação do Comitê de Ética em Pesquisa. Resultados: Considerando o fato de que metade do quantitativo de mulheres era primigesta, a maioria usava contraceptivo oral, não usava preservativo e nem participava do planejamento reprodutivo. Os dados revelaram que a autonomia reprodutiva das mulheres quilombolas sofre interferência do patriarcado, entretanto, vem se remodelando com a independência financeira das mulheres. Após agregação das unidades de registro, emergiram três categorias: "Teria que casar e ter filho(a)!", "Marcas da submissão e a conquista da autonomia" e "Planejamento reprodutivo: conflitos entre liberdade e obrigação". Conclusão e implicações para a prática: condições de vida desfavoráveis impedem mulheres quilombolas de vivenciarem a autonomia reprodutiva em plenitude; o conhecimento dessas condições poderão revelar reais necessidades de saúde reprodutiva e subsidiar ações direcionadas a este público.

Palavras-chave: Mulheres; Grupos Étnicos; Saúde Reprodutiva; Autonomia Pessoal; Condições Sociais.

\section{Abstract}

Objective: to explain the interference of the living conditions of quilombo women in reproductive autonomy. Method: this is a qualitative study with 10 quilombo women aged between 23 and 49 years old, living in rural communities of the Identity Territory of Bahia Productive backlands. They attended the meetings and signed the Free and Informed Consent Form. Data were collected through focus groups and analyzed by Bardin's thematic analysis. NVivo software was used to organize the data. Data collection took place after approval by the Research Ethics Committee. Results: Considering the fact that half of quantitative was primigravida women, the majority used oral contraceptives, did not use condoms, nor did they participate in reproductive planning. The data revealed that the reproductive autonomy of quilombo women suffers interference from patriarchy, however, it has been remodeling with the financial independence of women. After aggregating the registration units, three categories emerged: "I would have to marry and have a child!", "Marks of submission and the achievement of autonomy" and "Reproductive planning: conflicts between freedom and obligation". Conclusion and implications for practice: unfavorable living conditions prevent quilombo women from fully experiencing reproductive autonomy; knowledge of these conditions may reveal real reproductive health needs and subsidize actions directed to this public.

Keywords: Women. Ethnic Groups; Reproductive Health; Personal Autonomy; Social Conditions.

\section{Resumen}

Objetivo: explicar la interferencia de las condiciones de vida de las mujeres de palenques en la autonomía reproductiva. Método: Se trata de un estudio cualitativo con 10 mujeres de palenques de entre 23 y 49 años de edad, residentes en comunidades rurales del Territorio de Identidad del Sertão Productivo de Bahía. Asistieron a las reuniones y firmaron el Término de Consentimiento libre e informado. Los datos fueron recolectados a través de grupos focales y analizados por el análisis temático de Bardin. Se usó el software NVivo para organizar los datos. La recolección tuvo lugar después de la aprobación del Comité de Ética en Investigación. Resultados: Teniendo en cuenta el hecho de que la mitad de las mujeres eran primigestas, la mayoría de ellas utilizaban anticonceptivos orales, no utilizaban preservativos ni participaban en la planificación reproductiva. Los datos revelaron que la autonomía reproductiva de las mujeres de palenques sufre la interferencia del patriarcado, sin embargo, se ha ido remodelando con la independencia financiera de las mujeres. Después de la agregación de las unidades de registro, surgieron tres categorías: "¡Tendría que casarme y tener un hijo!", "Marcas de sumisión y el logro de la autonomía” "ylanificación reproductiva: conflictos entre libertad y obligación". Conclusión e implicaciones para la práctica: las condiciones de vida desfavorables impiden a las mujeres de palenques experimentar una plena autonomía reproductiva; el conocimiento de estas condiciones puede revelar las necesidades reales de salud reproductiva y subvencionar acciones dirigidas a este público.

Palabras clave: Mujeres; Grupos Étnicos; Salud reproductiva; Autonomía Personal; Condiciones Sociales. 


\section{INTRODUÇÃO}

O alcance das decisões reprodutivas, caracterizado pela capacidade de controlar o número, o tempo e o espaçamento de gravidezes e nascimentos sofre influências de fatores individuais, familiares, sociais, comunitários e legais, tais como o conhecimento sobre métodos contraceptivos e saúde reprodutiva, habilidades relativas ao uso correto desses métodos, sentimentos e atitudes em relação à contracepção e padrões de comportamento sexual, além do acesso aos contraceptivos. ${ }^{1}$

A autonomia é uma concepção fundamental para o pleno exercício dos direitos sexuais e reprodutivos e vem sendo alcançada por meio das lutas do movimento feminista. Entretanto, as mulheres quando comparadas aos homens se encontram em desvantagem no que diz respeito aos direitos sexuais e reprodutivos, pelo seu papel ainda de submissão nas questões sexuais e de responsabilidade quase exclusiva nas questões reprodutivas, o que dificulta o diálogo com o parceiro e aumenta a vulnerabilidade. Desse modo, mudanças culturais e estruturais são essenciais para o alcance da igualdade de gênero nesse aspecto. $^{2,3}$

O empoderamento das mulheres, quando avaliado pela participação na tomada de decisões domésticas em relação à violência doméstica e à recusa de ter relações sexuais com o marido, não foi consistentemente associado ao desejo de famílias menores ou à capacidade de atingir a fertilidade desejada, em estudo realizado em países da África Subsaariana. Contudo, destaca-se a importância constatada por meio de outros estudos da associação entre o empoderamento das mulheres e as decisões reprodutivas, visto que muitas mulheres africanas desejam constituir famílias menores, mesmo sem a prática da contracepção. ${ }^{4}$

A garantia política em relação ao exercício pleno dos direitos reprodutivos é fundamental. No entanto, ainda que o acesso à anticoncepção seja um direito garantido pela Constituição, este não é amplamente atendido, o que resulta em uma atenção precária, excludente e até inexistente em algumas localidades e em certos grupos étnicos, prejudicando especificamente as mulheres pobres e residentes em áreas rurais. ${ }^{5}$

Assim, tanto o acesso aos serviços de planejamento reprodutivo, direito básico fundamental para as pessoas desfrutarem de uma vida reprodutiva saudável e com liberdade, quanto as questões relacionadas à saúde reprodutiva de mulheres quilombolas são não visibilizados. Os dados que possibilitam conhecer suas condições de vida e saúde praticamente inexistem. , $^{6,7}$

A experiência com o planejamento reprodutivo de mulheres quilombolas, revelada em estudo baiano, apontou para a falta de orientações por parte da família bem como pelos serviços de saúde sobre a concepção e métodos contraceptivos, durante a adolescência, o que revela uma restrição do direito reprodutivo por esse grupo social, marcada notadamente pela desigualdade quanto à raça/cor e outras condições desfavoráveis. ${ }^{7}$

Contudo, a oportunidade de estudo e a inserção no mercado de trabalho, conquistadas por algumas mulheres quilombolas, especialmente àquelas que se destacam na luta pelos seus direitos, tornam possível a independência financeira e o empoderamento feminino, características essenciais para a autonomia reprodutiva.

Desse modo, o presente estudo objetivou explicar a interferência das condições de vida de mulheres quilombolas na autonomia reprodutiva.

\section{MÉTODO}

Trata-se de um estudo qualitativo realizado com mulheres quilombolas, líderes de comunidades reconhecidas pela Fundação Palmares, localizadas na zona rural de um município de pequeno porte, integrante do Território de Identidade da Bahia Sertão Produtivo.

Os dados foram coletados mediante encontros de grupo focal e planejados conforme estudo de Prates et al., ${ }^{6}$ a partir de adaptações necessárias. Os encontros contaram com a participação de uma observadora e da autora principal do estudo como moderadora. Foram utilizados roteiros contendo questionamentos para estimular a discussão e as atividades propostas, que guiaram as sessões agendadas.

No primeiro encontro, após serem apresentadas as orientações quanto à operacionalização, os objetivos e as etapas estabelecidas, as participantes se apresentaram, escolheram um nome para colocar no crachá e foram convidadas a escutar a música "O Xote das Meninas" de Luiz Gonzaga. Ao término da música, foi perguntado às mulheres: "O que mais Ihes chamou a atenção na música?" "O que a música tem a ver com a vida de vocês ou das mulheres da comunidade onde moram?" "O que a música tem a ver com autonomia/liberdade reprodutiva?" Em seguida, foram distribuídas na roda, imagens (mulher com a mão na boca, casal se abraçando, pau de arara, estrada ruim, mãe com filhos/as, roda de dança de mulheres, equipe de saúde em atividade educativa, mulher grávida, mulheres na colheita, bonequinhos representando um casal com uma nuvem de pensamentos e uma família representada na nuvem) para que as mulheres escolhessem e colassem no cartaz para representar o que interfere na autonomia reprodutiva delas e das mulheres da comunidade onde moram; ao fim da construção do cartaz, teriam que explicar qual foi a imagem escolhida e o porquê da escolha. Toda a discussão foi conduzida a partir da reflexão em torno da temática da autonomia reprodutiva. Por fim, foi feita a síntese, a avaliação e o encerramento.

No segundo encontro, também foram apresentadas as orientações quanto à operacionalização, ao objetivo e às etapas. As participantes se apresentaram novamente, pois havia uma nova integrante no grupo e, então, foram distribuídos os crachás. Para propiciar a interação, cada mulher deveria escolher uma mensagem, ler e entregar à companheira que estivesse ao lado, como lembrança do mês da mulher. Em seguida, foi solicitado às mulheres que se olhassem em um espelho pequeno entregue a cada uma e dissessem qual era a mulher visualizada no espelho e se aquela mulher tinha autonomia reprodutiva. Foram, portanto, lidas algumas falas de quilombolas que participaram de uma pesquisa de mestrado ${ }^{7}$ referente às questões reprodutivas. Depois de ouvir as falas, elas teriam que comentar sobre o que 
escutaram, trazendo referência para a sua vida e a das mulheres da comunidade onde residem. Ao fim da reflexão das falas, tiveram que apontar palavras que lhe viessem à mente, representassem tudo o que tinha sido discutido e que se referissem aos fatores que interferiam na autonomia reprodutiva de quilombolas, para serem escritas em um cartaz afixado na parede. Por fim, foi feita a síntese, a avaliação e o encerramento do encontro.

Os encontros foram realizados na sede do Sindicato dos Trabalhadores Rurais, Agricultores e Agricultoras Familiares do município em que se localizam as comunidades do estudo. $\mathrm{O}$ primeiro no dia 23 de fevereiro de 2019, com duração de uma hora e meia, e o segundo no dia 16 de março de 2019, com duração de uma hora e quarenta e sete minutos, dentro do limite de tempo destacado por Gatti. ${ }^{8}$ Foi utilizado um gravador de áudio posicionado em local adequado (mediante autorização das participantes) e um diário de campo também utilizado para o registro de observações pertinentes à análise.

Participaram dos encontros 10 mulheres quilombolas representantes de sete comunidades localizadas no município. No primeiro encontro agendado, compareceram nove mulheres e, no segundo, seis mulheres, sendo que cinco das nove mulheres do primeiro encontro foram também no segundo, em que compareceu uma nova integrante que não esteve presente no primeiro.

Os critérios de inclusão das participantes do estudo foram: ser mulher líder (integrante da associação quilombola e/ou participante das lutas da comunidade), residente em comunidade quilombola do município, em idade reprodutiva, maior de idade (18 a 49 anos), que aceitasse participar mediante assinatura do termo de consentimento livre e esclarecido. A escolha de lideranças justifica-se pelo "lugar de fala" que estas possuem, representando as comunidades em diferentes espaços políticos, desde as negociações referentes à posse da terra, ou a outras demandas como educação, saúde, habitação. São também hábeis negociadoras junto ao poder público, trazendo respostas efetivas para as necessidades apontadas pelas comunidades.

As informações oriundas dos grupos focais começaram a ser analisadas imediatamente após o término do encontro, iniciando com a escuta sensível da gravação em local silencioso para a compreensão da fala. Concomitantemente, o conteúdo das falas foi transcrito em documento no programa Microsoft Word (versão 2007), de modo que também foram feitas notas no texto, para que todas as informações, inclusive as da comunicação não verbal, fossem captadas, permitindo, assim, o enriquecimento e a preservação da essência dos relatos das participantes.

Os dados foram analisados pela técnica de análise de conteúdo temática proposta por Bardin, ${ }^{9}$ seguindo as três etapas:

- Pré-análise: fase de organização e sistematização das ideias; quando as falas são transcritas e agrupadas para escolha dos documentos a serem analisados, formulação de hipóteses e indicadores que fundamentem a interpretação;
- Exploração do material: quando os dados brutos são transformados e agregados em unidades de registros através da codificação;

- Tratamento dos resultados, inferência e interpretação: terceira e última fase, quandVsível propor inferências e realizar interpretações, com o intuito de alcançar resultados significativos.

Com a finalidade de facilitar a visualização dos dados coletados e a formulação das categorias, através da organização sistemática das falas, utilizou-se o software NVIVO® 11

Os aspectos éticos dispostos na Resolução 466/2012 do Conselho Nacional de Saúde, que normatiza pesquisas que envolvem seres humanos no Brasil, foram respeitados. ${ }^{10} \mathrm{~A}$ pesquisa teve início após aprovação do Comitê de Ética em Pesquisa (CEP), pelo parecer no 2.245.127.

\section{RESULTADOS}

As mulheres quilombolas que participaram dos encontros de grupo focal tinham de 23 a 49 anos, eram em sua maioria casadas, lavradoras, católicas, negras, possuíam ensino fundamental e uma renda individual mensal inferior a um salário mínimo. Metade destas era primigesta, a maioria usava contraceptivo oral como método anticoncepcional, não utilizava preservativo e não participava do planejamento reprodutivo.

Mesmo tratando-se de uma pesquisa com mulheres negras, o quesito raça/cor foi incluído no perfil sociodemográfico das participantes e uma das casadas se autodeclarou branca. Vale destacar que na referida região, alguns quilombolas se casaram com mulheres não necessariamente nascidas nessas localidades e que, depois de casadas, passaram a fazer parte da comunidade. A inclusão de pessoas de pele clara é uma característica que pode ser identificada no quilombo contemporâneo, resultado de uniões "inter-raciais" e de novas configurações familiares. Alguns quilombos contemporâneos diferem dos históricos, onde habitavam escravos refugiados ou descendentes de negros escravizados, mas não necessariamente fugitivos. ${ }^{11}$

Após inserção das transcrições no software NVIVO ${ }^{2} 11$, agregação das unidades de registro através dos nós e a realização de inferências e interpretações, emergiram três categorias relacionadas à interferência das condições de vida de mulheres quilombolas na autonomia reprodutiva: "Teria que casar e ter filho(a)!", "Marcas da submissão e a conquista da autonomia" e "Planejamento reprodutivo: conflitos entre liberdade e obrigação".

\section{Teria que casar e ter filho(a)!}

Um fator social que interfere na autonomia reprodutiva das mulheres, destacado pelas mulheres quilombolas, foi a imposição da sociedade em relação ao casamento e, consequentemente, a constituição da prole. Contudo, a fala de uma liderança aponta para a desconsideração dessa imposição. O papel da mulher enquanto mãe foi valorizado, e o não alcance dessa condição apontado como algo ruim para as que o desejavam. 
Eu penso assim, a mulher já é um pouco, assim, podese dizer discriminada, quando ela chega na fase da adolescência, igual fala na música ( $\mathrm{O}$ xote das meninas de Luiz Gonzaga - utilizada como estímulo para discussão) que ela já não queria mais brincar de boneca, que ela só queria saber de namorar, talvez porque o corpo dela mudou todo mundo já achava que ela estava na idade de casar, o povo já pensa em encaminhar a gente para um casamento [...] Já teve caso do pessoal comentar de mim, por eu não casar, só que essas coisas não me influenciam não. Não me importo (P5, 36 anos).

A mulher quando ela passa a ser mãe é muito bom, fica alegre, faz parte de nossa vida, e também é ruim porque tem aquelas que não conseguem ser mãe também, para mim é muito bom porque eu já tive três filhas, com muito sofrimento porque durante 6 meses eu não como, eu não bebo, mais depois disso tudo é só alegria (P10, 31 anos).

Em uma das falas é possível ainda perceber uma justificativa religiosa para composição familiar, compreendendo a mulher não como submissa, mas como uma companheira do marido, que consegue o que deseja através do diálogo:

No fundo, no fundo, a gente precisa de um parceiro, mesmo que muita das vezes o nosso marido não aceita nossas sugestões, mas quando a gente chega em uma boa conversa, em uma boa conquista, a gente consegue dominar ele, não querer ser a mais na frente dele. Porque como tenho pouco conhecimento da bíblia, Deus formou um casal, formou um homem e ele viu que o homem necessitava de uma companheira, então o homem precisa não da mulher para mandar no marido e sim para auxiliar, de uma auxiliadora para estar ali ao lado do marido (P7, 38 anos).

Outra problemática destacada pelas mulheres quilombolas refere-se às "mães solteiras", assim denominadas por elas. Para elas, a presença de um companheiro traz mais facilidade na criação dos(as) filhos(as) e evita a discriminação social.

Aquela mulher que tem seu companheiro sofre bem menos que aquela que têm os seus filhos sozinha. Eu sei, eu falo disso porque eu tenho a minha irmã que tem 5 filhos e cria os seus filhos sozinha, sei a dificuldade, a luta, ela não tem um desabafo, um companheiro para estar ali compartilhando a dificuldade de criar os seus filhos (P7, 38 anos).

E essa outra imagem (utilizada para a construção do cartaz) eu também achei muito interessante, porque retrata uma mãe solteira, e eu também sou uma mãe solteira e como ela falou, por falta de não ter um homem sua vida fica na boca dos outros, mas ninguém se coloca no lugar para saber do que ela passa para sustentar esses filhos sozinha (P5, 36 anos).

Apesar da imposição social pelo casamento e constituição da prole, o número de filhos(as) vem reduzindo, segundo as mulheres quilombolas do estudo. $O$ que segue a tendência nacional da queda da taxa de fecundidade.

Antes, quando a gente ia falar para um casal da comunidade de todo ano ter um filho, o marido falava que não, que mulher dele foi feita para parir. Aí quando chegou um tempo, ele virou para mim: "ah, se naquele tempo eu tivesse te ouvido, eu não estava padecendo hoje". Porque ele já era um homem de idade naquela época, ele com uma mulher nova fez muito filho e chegou a consequência que ele não tinha mais força para trabalhar (P3, 49 anos).

É algo gritante, é a realidade de muitos e dá para ver porque meus bisa teve 18 , meus bisa não, meu tatara teve 18 , meu bisa 7 , minha avó teve 7 também e mainha só teve 2, aí deu para ver que com o passar do tempo o povo foi aprendendo, foi modificando, foi tendo escolha, e antigamente não era uma escolha, era a natureza que deixava seguir o rumo da natureza ( $\mathrm{P} 4,23$ anos).

Em síntese, as mulheres quilombolas pontuaram que, apesar da imposição social, elas estão conquistando a liberdade para as decisões reprodutivas.

As mulheres estão conquistando sua liberdade aos poucos, embora têm alguns problemas, sofrem com o preconceito da sociedade e também da questão masculina, mas em geral as mulheres estão conseguindo conquistar seu espaço no mundo, estão conseguindo decidir se na verdade querem ter filhos, se deixam de querer ter filhos, quantos filhos querem ter, mesmo com a questão da sociedade em si (P4, 23 anos).

Eu vejo (no espelho - dinâmica para estímulo da discussão) uma mulher guerreira, batalhadora, sou mãe, mãe solteira. Esou muito feliz, graças a Deus sou livre, ninguém interfere em minha vida. Sou bastante independente, na minha vida reprodutiva também é dessa forma, então sou muito feliz com isso, e até hoje na minha vida, graças a Deus, não tenho arrependimento de nada, e principalmente na minha vida reprodutiva ( $\mathrm{P} 6,30$ anos).

\section{Marcas da submissão e a conquista da autonomia}

Outro fator social apontado pelas mulheres quilombolas como limitador da autonomia reprodutiva é a submissão feminina. Relatam que essa questão vem mudando, mas que as decisões de muitas mulheres da comunidade ainda sofrem interferência e imposições dos maridos/companheiros. 
$\mathrm{Na}$ comunidade ainda tem aqueles homens que não aceitam a mulher usar anticoncepcional, que não aceita a mulher fazer prevenção. Então isso ainda é a realidade do nosso município, não 100\% (P8, 44 anos).

Acredito que bem no fundo, no fundo do baú, ainda tem homem que tenta dominar o desejo da mulher, e elas acabam, não em sua totalidade, mas elas acabam indo ainda pela vontade do marido. Ainda hoje os homens tentam manipular as mulheres (P9, 41 anos).

Antes, nós mulheres éramos um pouco presas, donas de casa, destinadas a ter filhos, cuidar dos filhos, só para trabalhar em casa, dedicar sua vida ao esposo. E hoje não, hoje a mulher já trabalha fora, mas só que nós temos que fazer com que isso aconteça, não podemos baixar a cabeça. Erguer a cabeça e não aceitar o que o marido diz. Porque antes não, antes era obrigatório, tinha que aceitar. E hoje não, hoje a mulher tem uma fala (P3, 49 anos).

O diálogo entre marido e mulher é um fator familiar apontado pelas participantes como uma possível solução para a submissão feminina. Contudo, o diálogo parece ser algo difícil de se alcançar no relacionamento, sendo necessário "falar com jeito".

Mas essa liberdade depende muito de combinação, por exemplo, se seu esposo é uma pessoa difícil de entender tem que ir levando com jeito, "é por isso, é dessa forma". Hoje está difícil, quanto mais filhos você tem, mais a dificuldade vai aumentando, não é igual a antigamente, que nossos pais, nossos avós tinham um atrás do outro e criava tudo por igual, mas hoje é difícil, o gasto hoje é total difícil (P8, 44 anos).

Na nossa comunidade hoje, graças a Deus, as mulheres conseguem conversar com o marido para decidir se vão ter ou se não vão ter. Só que antigamente não tinha isso não, era só reproduzir, tinha que reproduzir, não conhecia nenhum método, nenhum anticoncepcional e aquelas que conheciam, o marido não deixava utilizar, mas hoje todo mundo já tomou essa consciência (P5, 36 anos).

A independência financeira, conquistada por algumas mulheres, mas não bem vista pelos homens, surge como um fator individual apontado pelas mulheres quilombolas como um facilitador para a autonomia.

Eu escolhi aquela imagem que a mulher está com a mão na boca, porque antigamente a mulher não tinha autoridade e liberdade para poder falar e decidir as coisas, só que hoje quando a mulher é independente tem mais liberdade de escolher as coisas na vida dela, então aquela imagem reflete muito isso ( $\mathrm{P} 6,30$ anos).

Acho que minha comunidade não é diferente das de vocês, que sempre as mulheres tão à frente, homem pingado e mulher tá lá tomando conta, e tem homem que ainda quer ser machista, ele não aceita isso que a mulher seja independente (P3, 49 anos).

A busca da autonomia, segundo as mulheres quilombolas do estudo, se dá pela capacitação, pelo trabalho e até por grupos de mulheres que se encontram para reforçar a cultura da comunidade, produzir e ainda aumentar a renda com a venda dos produtos.

Essa imagem aqui retrata o grupo de mulheres, que nós também temos na nossa associação um grupo de mulheres que fazem doces e artesanatos. E o grupo de mulheres também fortalece as mulheres da comunidade, faz com que as mulheres tenham autonomia, também por passar dificuldades faz com que até aumente a sua autoestima, e em caso de reprodução como você fala. $E$ também achei muito interessante a cultura, que a cultura tem que ser valorizada, a mulher tem que ter seu momento de alegria (P5, 36 anos).

Hoje tem o mercado, está oferecendo esse trabalho, então cabe a gente buscar, aperfeiçoar e não ficar para trás, e não ficar dependendo sempre, ser escrava do marido (P3, 49 anos).

\section{Planejamento reprodutivo: conflitos entre liberdade e obrigação}

Para estas mulheres, a responsabilidade pelo planejamento reprodutivo é toda direcionada para a mulher. Entretanto, na maioria das vezes, essa responsabilidade não é entendida como liberdade de escolha, mas como uma obrigação para prevenção.

Em todo caso, quem tem que tomar a injeção é a mulher, quem tem que tomar a pílula é a mulher, se for usar o DIU é a mulher, a questão do homem fica só na camisinha $e$ se depender do homem e a mulher não falar nada tem a relação sem a camisinha, então a questão de prevenir é toda da mulher (P4, 23 anos).

Essa menina minha aí eu fiquei com ela 16 anos, só depois que fui arrumar essa outra, mas porque eu coloquei o DIU, e coloquei sozinha também, não tive marido para ir lá comigo não. Coloquei o DIU e fiquei 11 anos com ele, depois que eu tirei tomei injeção e com 15 dias engravidei dessa, aí agora eu consegui, com fé em Deus eu consegui minha laqueadura (P2, 37 anos).

O planejamento reprodutivo é entendido pelas participantes do estudo como responsabilidade exclusiva das mulheres; não que deva ser, mas é o que se observa. Expressam que, quando se trata da laqueadura, a assinatura do cônjuge é necessária, e mesmo não conhecendo bem os critérios para tal procedimento, 
as mulheres quilombolas parecem incomodar-se com essa imposição.

Eu tenho uma pequena impressão que essa liberdade é meio assim, como eu posso dizer, ilusória. Porque a questão é o seguinte, a mulher tem toda uma liberdade sim, mas na hora que for fazer uma laqueadura ela precisa da assinatura do marido, ela não pode decidir em não ter nenhum filho, porque os médicos só pegam assinatura a partir do momento que tem três filhos e 35 anos, então essa liberdade é meio ilusória, você não tem total liberdade sobre o seu corpo afinal [...] Acho absurdo, o cúmulo do absurdo homem ter que assinar pra mulher operar. O corpo é meu, eu faço dele o que eu quiser (P4, 23 anos).

Eu acho que tudo cai em cima da mulher, porque eu sou mãe de seis filhos, primeiro eu tive os quatro, aí a caçula era essa menina aí, aí o povo falava "faz a laqueadura", aí eu perguntava o meu esposo e ele dizia: "ah, mas hoje eu não tenho gasolina", "ah, mas amanhã eu vou sair" [...] Não, ele não tava importando com filho, eu falo a verdade, ele é um excelente marido, tudo que eu falar ele concorda, mas isso daí ele não concordou não (laqueadura). Isso daí eu não sei se é porque ele queria ter mais filho, não sei o que era, ou se era dó de perder um dia de serviço, e eu não sei, só sei que ele não queria (P2, 37 anos).

Destacam a dificuldade de os homens em realizar a vasectomia, pois alegam reduzir a virilidade masculina, o que aumenta ainda mais a responsabilidade feminina pelo planejamento reprodutivo.

Mas essa questão é daquele homem machista, que acha que se ele for fazer isso daí ele não é mais homem, então falta muita orientação também nesses tipos de coisa, porque na minha região já tem homem que decidiu fazer a laqueadura, porque tem a laqueadura masculina, então eles já decidiram, conheci um só que fez a cirurgia (P8, 44 anos).

Com certeza, é realidade em minha região também, inclusive a gente tem casos lá que a mulher tem todo tipo de problema, tem outra cirurgia para fazer porque deu problema com pedra na vesícula e o marido não faz nada, ao contrário, tem havido uma luta para ver se ele pelo menos assina para ela fazer a ligação. E ele não quer ligar porque tá machista, poderia ele ligar, fazer a laqueadura e não ela, pelo risco de ter vários problemas de saúde nela. Então, com certeza, a responsabilidade fica toda para a mulher (P6, 30 anos).

O "conhecimento" também é destacado como fator individual que interfere nas decisões reprodutivas, porque, na verdade, muitas vezes, nem escolhas são, as gestações acontecem por falta de conhecimento.
No quilombo onde eu moro eu acho que se fizer uma média lá do pessoal ainda vivem nessa vida, de não conhecer para evitar. Hoje tem mulheres lá que na idade de quase aposentar tem filhos de menor ainda. Que não conheciam nenhum método, e foi tendo filho um atrás do outro, e não teve opção (P5, 36 anos).

Muitas mulheres já caíram nessa vida reprodutiva cedo, por falta de informação, e achando talvez que era uma coisa e, no final, pela falta de informação, não era, e se deram mal. Porque talvez se soubessem iriam se prevenir (P8, 44 anos).

Hoje, por mais que tenham muitas informações, que as mães conversem bastante com os filhos, hoje acontece de adolescentes serem mães muito novas e isso perde de curtir a juventude, perde de estudar, futuramente tem uma criança muito nova e não tem assim uma base financeira para conseguir educar o filho de uma forma melhor. Eu tenho 30 anos, e na minha época minha mãe não falava nada disso com a gente. Então, tipo assim, graças a Deus eu tive uma cabeça até melhor, tive meu filho com 24 anos, mas a minha mãe, o jeito dela nos criar, ela não falava isso (P6, 30 anos).

\section{DISCUSSÃO}

Os papéis definidos para as mulheres na sociedade ao longo da história determinavam, e em alguns casos, ainda determina, as suas decisões reprodutivas. As pressões sociais para o casamento e concepção são vivenciadas por muitas mulheres logo no início da fase adulta, especialmente por aquelas pertencentes a certos grupos étnicos e/ou que residem em comunidades ainda com fortes marcas do patriarcado, como as comunidades rurais quilombolas.

Por muito tempo, o casamento foi a única maneira de as mulheres obterem uma identidade social e o contrato matrimonial, atrelado ao patriarcalismo, baseava-se na sujeição da mulher ao homem, inclusive nos processos de decisões e escolhas reprodutivas. $^{2}$

Tal imposição social pelo casamento conduz muitas mulheres ao sofrimento psíquico diante da sua condição de separada, e, caso tenham filho(a), são denominadas "mães solteiras", o que aumenta o preconceito. Fato relatado e percebido também nas expressões não verbais das participantes que tiveram ou têm essa realidade vivenciada.

Desde o período colonial, há relatos de genitores masculinos que não reconheciam seus/suas filhos(as), geralmente por relacionamentos extraconjugais com mulheres pobres, negras e condenadas socialmente a serem solteiras e objetos sexuais de seus patrões. Essa realidade continuou no século $X X$, quando os(as) filhos(as) das mulheres negras não representavam mais aumento do número de escravos para seus Senhores, mas continuavam a nascer como filhos(as) de pais desconhecidos. Atualmente, algumas mulheres se libertaram do mundo privado, 
estudaram, inseriram-se no mercado de trabalho e alcançaram a autonomia de liderarem sozinhas uma família, entretanto, essa não é uma realidade das mulheres pobres, que historicamente foram chefes de família, mas não por escolha. ${ }^{12}$

A religião também aparece como justificativa para a necessidade de constituição familiar, e, nesse caso, os registros bíblicos são a comprovação de que Deus criou a mulher para ser companheira do homem e ordenou que perpetuassem a espécie.

A atribuição à força divina sobre a decisão do seu futuro e de sua prole é algo apontado em estudo realizado com mulheres quilombolas do Recôncavo da Bahia, que, mesmo não desejando a gravidez, são obrigadas a aceitá-la por ser esse um comportamento socialmente esperado. ${ }^{7}$

Entretanto, com a inserção da mulher no mercado de trabalho e o aumento da escolaridade a taxa de fecundidade tem diminuído o que resulta na redução da prole de diversas famílias, ${ }^{13}$ inclusive daquelas que residem em comunidades quilombolas rurais, como destacam as participantes da pesquisa ao traçar um comparativo entre o número de filhos(as) de suas avós, mães e os(as) delas.

Mulheres quilombolas do Recôncavo Baiano declaram não se arrepender do número de filhos(as), mas atestam que precisam trabalhar muito com seus parceiros para prover o sustento da casa, desse modo, alegam não desejar repetir essa experiência e já conversam com seus filhos(as) sobre esse assunto. ${ }^{7}$

A independência financeira é entendida como principal fator que contribui positivamente para a autonomia das mulheres, inclusive nas questões reprodutivas. Nessa condição, ela pode decidir por si já que não depende do marido/companheiro financeiramente, esse não é mais "seu dono". Para a busca dessa independência, a participação em grupo de mulheres, muito presentes nas comunidades quilombolas, é destacada como importante resgate à cultura, através do artesanato e culinária, e ainda possibilita o aumento da renda.

Estudos realizados com mulheres quilombolas apontam para condições socioeconômicas precárias, o que dificulta a independência financeira dessas mulheres. ${ }^{7,14,15} \mathrm{O}$ desemprego entre as mulheres negras é muito maior em comparação com as taxas entre as brancas. ${ }^{5}$ Muitas mulheres quilombolas do Sertão Produtivo, inclusive, passam meses fora de casa à procura de emprego nas lavouras do Sudeste, local com mais chuva e mais oportunidades de trabalho. Dessa maneira, quando a redução da prole não se dá pela inserção da mulher no mercado de trabalho, dá-se pelas dificuldades financeiras, entendida hoje como problema para criação dos(as) filhos(as). ${ }^{7,12,13}$

Mesmo diante de melhorias identificadas em relação à submissão feminina, situações de imposição masculina foram relatadas pelas mulheres líderes quilombolas como algo ainda presente na vida de algumas mulheres da comunidade, principalmente entre as casadas e dependentes financeiramente. Enquanto líderes, elas se mostram mais certas de suas escolhas e com maiores condições de alcançar a autonomia, sendo importantes incentivadoras e agentes de mudança dentro da comunidade.
O diálogo é trazido pelas mulheres líderes quilombolas como um fator importante para o rompimento da desigualdade de gênero. Elas incentivam e encorajam as mulheres da comunidade ao diálogo, mesmo que muitas vezes essa tarefa não seja fácil.

O pouco diálogo sobre o uso de métodos contraceptivos é uma constante na vida de muitos casais, e essa incapacidade de negociar o planejamento reprodutivo sofre influências das normas de gênero. ${ }^{16}$ Influência essa também identificada em estudo realizado com homens no sul de Moçambique sobre percepções e experiências no planejamento reprodutivo. ${ }^{17}$

Estudo sobre a vulnerabilidade ao HIV/AIDS no contexto brasileiro e as iniquidades de gênero, raça e geração demonstrou que o diálogo sobre o uso de preservativos e a prevenção das infecções sexualmente transmissíveis, apesar de dificultado entre as jovens e solteiras, é ainda pior entre as casadas, o que pressupõe ausência de confiança sobre seu parceiro ou, até mesmo, alguma suspeita sobre sua própria fidelidade. ${ }^{18}$

Um estudo de revisão sistemática apresenta a coerção reprodutiva como um fenômeno que afeta desproporcionalmente mulheres vítimas de violência por parceiro íntimo, mulheres de menor nível socioeconômico, mulheres solteiras e mulheres afro-americanas e multirraciais. ${ }^{19}$

Estudo realizado com mulheres atendidas em uma clínica pública de saúde reprodutiva em uma cidade de Gana aponta uma prática comum entre as mulheres na África Subsaariana: 0 uso sigiloso de contraceptivos, que consiste na prática de usar um método anticoncepcional sem o conhecimento do parceiro. Este fato é considerado sintomático da falta de capacidade da mulher para exercer livremente seus direitos reprodutivos. ${ }^{20}$

A objeção do marido foi um dos motivos mais comuns mencionados por mais de $70 \%$ das mulheres participantes em estudo na Etiópia para o não uso dos métodos de planejamento familiar. ${ }^{21} \mathrm{E}$ estudo realizado na República Democrática do Congo aponta que as mulheres podem enfrentar barreiras ao uso da contracepção devido à autonomia limitada na tomada de decisões, o que provavelmente reflete uma dinâmica desigual de poder entre mulheres e homens nas residências. ${ }^{22}$

Apesar da submissão feminina, ainda hoje presente em diversas situações, à mulher é dada a responsabilidade no planejamento reprodutivo. Responsabilidade essa que leva a uma falsa sensação de autonomia, pois o agir é conforme o que é imposto e, quando ocorre algo inesperado, no que tange às decisões reprodutivas do casal, a mulher é tida como a única responsável. Outra questão discutida nesse quesito se refere à autorização do cônjuge na laqueadura, o que ora é entendida como mais uma atitude machista, que limita a mulher diante de uma decisão sobre seu próprio corpo, ora como uma maneira de proporcionar a decisão entre o casal.

Diversos estudos, seja na visão das mulheres, seja dos(as) profissionais de saúde e dos próprios homens, apontam para o afastamento masculino dos serviços de planejamento familiar, resultante do imaginário do homem como invulnerável ou da compreensão do planejamento reprodutivo como responsabilidade feminina, assim, a mulher assume a contracepção como atividade 
de sua responsabilidade e o papel desempenhado pelo parceiro é uma função acessória, quando acontece..$^{15,16,23-25}$

Estudo realizado com mulheres quilombolas do Recôncavo Baiano aponta que a prevenção da gravidez é colocada socialmente como "coisa de mulher", que os homens não se sentem responsáveis e que são excluídos dos serviços de saúde, além de não os apresentarem como corresponsáveis pela gravidez e criação dos(as) filhos(as), ainda que a lei do Planejamento Familiar os aponte como parte integrante do conjunto de ações de atenção à mulher, ao homem ou ao casal. Desse modo, a escolha pelo método contraceptivo é feita unicamente pelas mulheres sem qualquer interferência dos seus parceiros ou mesmo alguma combinação. ${ }^{7}$

E, "ao escolher sozinha e se responsabilizar pela contracepção a mulher exime o parceiro de uma atribuição que é de ambos, reforçando a ideia socialmente construída, e aceita, consciente ou inconscientemente, de que são encarregadas dos assuntos reprodutivos". 25:659

Outro fator apontado como determinante para a autonomia reprodutiva foi o conhecimento sobre a concepção e os métodos contraceptivos. Apesar de as informações estarem chegando aos lugares mais longínquos, especialmente através da internet, muitas mulheres quilombolas não exercem a autonomia para as escolhas reprodutivas por desconhecerem os métodos para evitar a gravidez. Atrelado a isso pode-se apontar a pouca escolaridade e o distanciamento dos serviços de saúde.

O Relatório das Desigualdades de Raça, Gênero e Classe ${ }^{26}$ aponta que homens e mulheres não brancos possuem uma média de dois anos a menos de escolaridade em comparação com homens e mulheres brancos.

O desconhecimento quanto ao planejamento reprodutivo e o não comparecimento às Unidades Básicas de Saúde por populações quilombolas podem ser explicados, principalmente, pela distância entre as comunidades rurais e os serviços de saúde. Assim, a falta de informações e orientações sobre o uso de métodos contraceptivos contribuem para gravidezes indesejadas e escolha pela laqueadura precocemente., ${ }^{7,27}$

O desconhecimento pode levar também à perpetuação do preconceito diante da vasectomia, compreendida ainda por muitos como responsável por problemas correlacionados à ereção masculina.

Estudo de revisão integrativa, o qual buscou descrever o conhecimento científico sobre a participação do homem no planejamento familiar, demonstrou que, apesar de os homens se mostrarem satisfeitos após que terem sido submetidos à vasectomia, inúmeros receios estão ainda presentes, principalmente no que se refere à desvalorização enquanto "homem", o que faz com que sua prática ainda não seja comum, apesar de seus benefícios já comprovados. ${ }^{23}$

Diante de toda essa problemática, uma mulher quilombola participante do estudo destaca atividades educativas direcionadas aos homens como uma estratégia de intervenção, algo possível de se desenvolver e uma ação inovadora diante dos estudos da área.

\section{CONCLUSÃO}

Os dados provenientes dos dois encontros de grupo focal realizados demonstram que a autonomia reprodutiva das mulheres quilombolas das comunidades estudadas sofre interferência do patriarcado, mas que vem se remodelando a partir da conquista da independência financeira por parte de algumas mulheres, como as líderes participantes dos encontros, que demonstraram certo poder sobre o corpo, o trabalho e as decisões reprodutivas.

A partir dos resultados apresentados, conclui-se que condições sociais, econômicas e individuais desfavoráveis, as quais, por sua vez, contribuem para um maior nível de desigualdade, impedem mulheres quilombolas de vivenciarem a autonomia reprodutiva em sua plenitude.

A vida de mulheres quilombolas é ainda marcada pela imposição social dos padrões patriarcais de submissão aos companheiros. Por outro lado, a ausência de diálogo e, muitas vezes, a dificuldade de obter informações e ausência de serviços de saúde limitam o acesso ao planejamento reprodutivo.

Contudo, vale destacar a diminuição da imposição masculina relatada pelas mulheres líderes quilombolas, especialmente, dentre àquelas que alcançaram a emancipação, seja pela independência financeira, seja pela participação política ou mesmo pelas mudanças dos padrões sociais. Estas conquistas representam avanços no que se refere à autonomia reprodutiva e mostram a possibilidade de saída da condição de submissão.

O uso de ações educativas que utilizam métodos reflexivos pode ampliar a compreensão sobre a reprodução com responsabilidade compartilhada, incluindo a coparticipação na educação de filhas e filhos, fundamentais para construir a igualdade de gênero.

Destaca-se a contribuição deste estudo para população em geral e para a área de saúde, pois os resultados poderão dar visibilidade às condições de vida de mulheres quilombolas e às suas reais necessidades de saúde reprodutiva e, com isso, subsidiar ações direcionadas a esse público.

\section{CONTRIBUIÇÕES DOS AUTORES}

Desenho do estudo. Elionara Teixeira Boa Sorte Fernandes; Sílvia Lúcia Ferreira.

Coleta ou produção dos dados. Elionara Teixeira Boa Sorte Fernandes.

Análise de dados e interpretação dos resultados. Elionara Teixeira Boa Sorte Fernandes; Sílvia Lúcia Ferreira; Cláudia Suely Barreto Ferreira; Verônica Barreto Cardoso.

Redação e revisão crítica do manuscrito. Elionara Teixeira Boa Sorte Fernandes; Sílvia Lúcia Ferreira; Cláudia Suely Barreto Ferreira; Verônica Barreto Cardoso.

Aprovação da versão final do artigo. Elionara Teixeira Boa Sorte Fernandes; Sílvia Lúcia Ferreira; Cláudia Suely Barreto Ferreira; Verônica Barreto Cardoso.

Responsabilidade por todos os aspectos do conteúdo e a integridade do artigo publicado. Elionara Teixeira Boa Sorte Fernandes; Sílvia Lúcia Ferreira; Cláudia Suely Barreto Ferreira; Verônica Barreto Cardoso. 


\section{EDITOR ASSOCIADO}

Aline Aparecida Monroe

\section{REFERÊNCIAS}

1. Upadhyay UD, Dworkin SL, Weitz TA, Foster DG. Development and validation of a reproductive autonomy scale. Stud Fam Plann. 2014;45(1):19-41. http://dx.doi.org/10.1111/j.1728-4465.2014.00374.x.

2. Souzas R, Alvarenga AT. Direitos sexuais, direitos reprodutivos: concepções de mulheres negras e brancas sobre liberdade. Saude Soc. 2007 ago;16(2):125-32. http://dx.doi.org/10.1590/S010412902007000200012.

3. Santos NJS. Mulher e negra: dupla vulnerabilidade às DST/HIV/aids. Saude Soc. 2016 set;25(3):602-18. http://dx.doi.org/10.1590/s0104129020162627.

4. Upadhyay UD, Karasek D. Women's empowerment and ideal family size: an examination of DHS empowerment measures in sub-saharan Africa. Int Perspect Sex Reprod Health. 2012 jun;38(02):78-89. http:// dx.doi.org/10.1363/3807812.

5. Secretária Especial de Políticas para as Mulheres (BR). Plano Nacional de políticas para as mulheres [Internet]. Brasília; 2004 [citado 2004 Ago 7]. Disponível em: http://bvsms.saude.gov.br/bvs/publicacoes/PNPM. pdf

6. Prates LA, Ceccon FG, Alves CN, Wilhelm LA, Demori CC, Silva $\mathrm{SC}$ et al. A utilização da técnica de grupo focal: um estudo com mulheres quilombolas. Cad Saude Publica. 2015 dez;31(12):2483-92. http:// dx.doi.org/10.1590/0102-311X00006715.

7. Pereira COJ, Ferreira SL. Experiências de mulheres quilombolas com planejamento reprodutivo e assistência no período gravídico-puerperal. Feminismos. 2016;4(3):47-61.

8. Gatti BA. Grupo focal na pesquisa em Ciências Sociais e Humanas. Brasília: Líber Livro Editora; 2005.

9. Bardin L. Análise de conteúdo. 5. ed. Lisboa: Edições 70; 2016

10. Resolução no 466 de 12 de dezembro de 2012 (BR). Diário Oficial da União, Brasília (DF), 13 jun 2012.

11. Mussi RFF, Mussi LMPT, Bahia CS, Amorim AM. Atividades físicas praticadas no tempo livre em comunidade quilombola do alto sertão baiano. Licere. 2015;18(1):157-87. http://dx.doi.org/10.35699/19813171.2015 .1080

12. Oliveira RS. Mães solteiras e a ausência do pai: questão histórica e novos dilemas. Elaborar. 2015;3(1):79-91.

13. Marion Filho PJ, Reichert $\mathrm{H}$. Condicionantes econômicos e sociais da fecundidade no Brasil. Cienc Soc Perspect. 2017;16(30):39-57. http:// dx.doi.org/10.5935/1981-4747.20170003.

14. Oliveira SKM, Pereira MM, Freitas DA, Caldeira AP. Saúde maternoinfantil em comunidades quilombolas no norte de Minas Gerais. Cad
Saude Colet. 2014 set;22(3):307-13. http://dx.doi.org/10.1590/1414462X201400030013.

15. Oliveira MV, Guimarães MDC, França EB. Fatores associados a não realização de Papanicolau em mulheres quilombolas. Cien Saude Colet. 2014 nov;19(11):4535-44. http://dx.doi.org/10.1590/1413812320141911.15642013.

16. Morais ACB, Ferreira AG, Almeida KL, Quirino GDS. Participação masculina no planejamento familiar e seus fatores intervenientes. Rev Enferm UFSM. 2014 nov 19;4(3). http://dx.doi.org/10.5902/217976929998.

17. Pedro VM, Mariano EC, Roelens K, Osman NMRB. Percepções e experiências dos homens sobre o planejamento familiar no sul de Moçambique. Physis Rev Saúde Coletiva. 2016 out;26(4):1313-33. http://dx.doi.org/10.1590/s0103-73312016000400013.

18. Garcia S, Souza FM. Vulnerabilidades ao HIV/aids no Contexto Brasileiro: iniquidades de gênero, raça e geração. Saude Soc. 2010 dez;19(Supl. 2):9-20. http://dx.doi.org/10.1590/S0104-12902010000600003.

19. Grace KT, Anderson JC. Reproductive coercion: a systematic review. Trauma Violence Abuse. 2018 Oct;19(4):371-90. http://dx.doi. org/10.1177/1524838016663935.

20. Baiden F, Mensah GP, Akoto NO, Delvaux T, Appiah PC. Covert contraceptive use among women attending a reproductive health clinic in a municipality in Ghana. BMC Womens Health. 2016;16(1):31. http:// dx.doi.org/10.1186/s12905-016-0310-x.

21. Alemayehu M, Lemma H, Abrha K, AdamaY, Fisseha G, Yebyo H et al Family planning use and associeted factors among pastoralist comunity of afar region, eastern Ethiopia. BMC Womens Health. 2016;16(39):1-9. http://dx.doi.org/10.1186/s12905-016-0321-7.

22. Sano Y, Antabe R, Atuoye KN, Braimah JA, Galaa SZ, Luginaah I. Married women's autonomy and postdelivery modern contraceptive use in the Democratic Republic of Congo. BMC Womens Health. 2018;18(49):1-7. http://dx.doi.org/10.1186/s12905-018-0540-1.

23. Nogueira IL, Carvalho SM, Tocantins FR, Freire MAM. Male participation in reproductive planning: an integrative review. Rev Pesqui Cuid Fundam Online. 2018 Jan 9;10(1):242. http://dx.doi.org/10.9789/2175-5361.2018. v10i1.242-247.

24. Casarin ST, Siqueira $\mathrm{HCH}$. Family planning and men's health from nurses' perspective. Esc Anna Nery Rev Enferm. 2014;18(4). http:// dx.doi.org/10.5935/1414-8145.20140094.

25. Cruz R, De Morais ACB, Pinto SDL, Amorim LTCG, Sampaio KJDAJ Participação masculina no planejamento familiar: o que pensam as mulheres? Cogitare Enferm. 2014 dez 19;19(4). http://dx.doi.org/10.5380/ ce.v19i4.37086

26. Leão N, Candido MR, Campos LA, Ferez Jr J. Relatório das desigualdades de raça, gênero e classe. Rio de Janeiro: Grupo de Estudos Multidisciplinares da Ação Afirmativa; 2018. (no. 2).

27. Gomes KO, Reis EA, Guimarães MDC, Cherchiglia ML. Utilização de serviços de saúde por população quilombola do Sudoeste da Bahia, Brasil. Cad Saude Publica. 2013 set;29(9):1829-42. http://dx.doi. org/10.1590/S0102-311X2013001300022. 